\title{
ROMANIAN
}

NEUROSURGERY

\author{
Vol. XXXIV | No. 2 June 2020
}

\section{Preoperative evaluation of superficial cortical venous drainage}

Surjeet Singh,

Stuti Kumari,

Abhijeet Sachan,

Shashi Kant Jain 


\title{
Preoperative evaluation of superficial cortical venous drainage*
}

\author{
Surjeet Singh ${ }^{1}$, Stuti Kumari ${ }^{2}$, Abhijeet Sachan ${ }^{1}$, Shashi Kant Jain ${ }^{1}$ \\ 1 SMS Medical College and Hospital, Jaipur, Rajasthan, INDIA \\ 2 Institute of Medical Sciences BHU Varanasi, Uttar Pradesh, INDIA
}

FULL TITLE: Preoperative evaluation of superficial cortical venous drainage around the lesion and localization of tumour boundaries preoperatively by applying cod liver capsule over the scalp with the help of MRI and MRV brain and comparison between 2-dimensional time-of-flight (2DTOF) and 3-dimensional contrast-enhanced magnetic resonance venography (3DCEMRV) brain in capsule marked cortical lesion and assessment of post-operative neurological outcomes.

\section{ABSTRACT}

Objectives and methodology: The preoperative exact localization of superficial intracranial lesions and superficial cortical veins is often necessary for making craniotomy and evaluation of cortical veins. We developed a simple and cheap method for such localization using cod liver oil capsule during the preoperative MRI and MRV brain examination. With the help of MRV brain, 3DCEMRV and 2DTOF images were taken and superficial cortical veins studied in the marked area for comparison between both modalities of MRV and planning of surgery for avoiding venous injury.

Results: Most of the cases were in the age group 16-60 years (91.6\%). The most common clinical manifestation was headache (85.4\%) and meningioma (60.4\%) was found to be the most common pathology. Clear visualization (Grade 3) of the individual superficial cortical vein was observed in 48 cases $(100 \%)$ in 3DCEMRV as compared to 2DTOF 22 cases (45.8\%) P <0.001S. Clear visualization (Grade3) of superior sagittal sinus was observed in 48 cases (100\%) in 3DCEMRV as compared to 2DTOF 33 cases $(68.6 \%)$ P <0.001S. In post-operative CT Head, we found $4(8.3 \%)$ cases were having venous infarction. 5 patients $(10.4 \%)$ developed motor weakness postoperatively. In 3 cases, postoperative MRV were done and found no venous injury.

Conclusion: This study showed that preoperative localization and evaluation of the tumoral area and cortical veins with the help of cod liver oil in MRI and MRV brain was very helpful in planning the surgery, making craniotomy and to avoid injury of the veins. This technique is easy to perform and the capsule is easily constructed and inexpensive. 3DCEMRV was found to be better modality than 2DTOF for delineation of veins. Final neurosurgical outcomes were better.

\section{INTRODUCTION}

Imaging of intracranial cortical venous system anatomy is important in planning neurosurgical operations of midline masses such as colloid cyst, DACA Aneurysm, Corpus callosal gliomas, parasagittal and

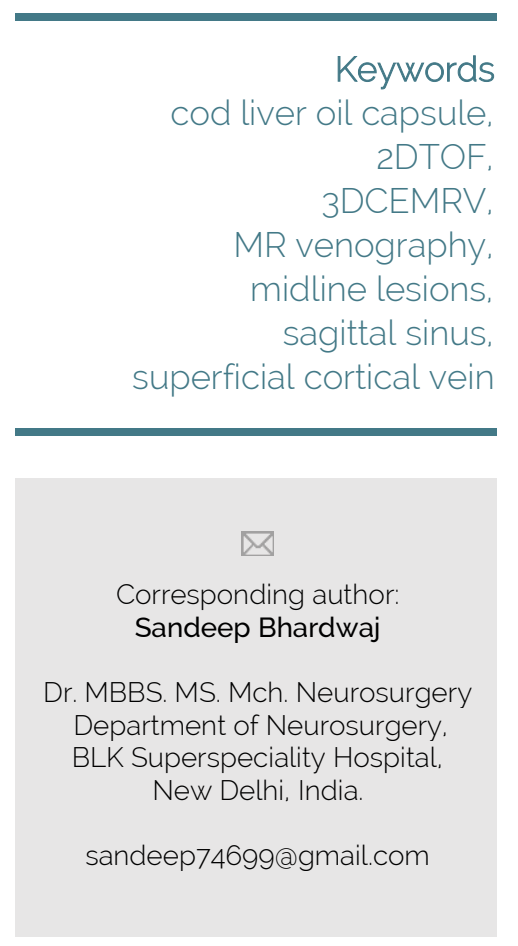

Copyright and usage. This is an Open Access article distributed under the terms of the Creative commons Attribution Non-Commercial No Commons Attribution Non-Commercial No
Derivatives License (https://creativecommons org/licenses/by-nc-nd/4.0/) which permits noncommercial re-use, distribution, and reproduction in any medium, provided the original work is unaltered and is properly cited.

The written permission of the Romanian Society of Neurosurgery must be obtained for commercial re-use or in order to create a derivative work.

ISSN online 2344-4959 (C) Romanian Society of Neurosurgery

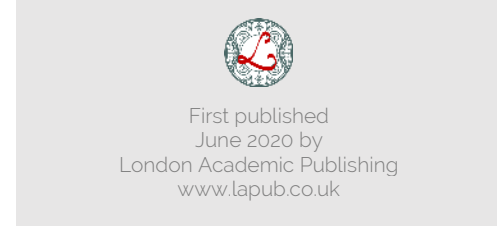


parafalcine masses and other midline brain tumors. Parafalcine masses may not be as closely related to the SSS as parasagittal tumors, but because of their close relation, their growth may also contribute to anatomical changes to the nearby cortical veins. During parasagittal tumors resection, saving the cortical veins is important as it offers normal venous drainage of the brain, as well as important collateral drainage. Disruption in venous outflow may result in venous infarction which leads to swelling, hemorrhage, neuronal death and may have catastrophic result $[1,2]$. MR Venography is very helpful to know the anatomic changes in the cortical veins and its relation with respect to tumor position before surgery so that it can be saved intraoperatively. Assessment of the patency of sagittal venous sinuses is very important to avoid major sinus injury, air embolism and catastrophic bleeding intraoperatively. Moreover, cortical vessels especially the veins are important landmarks in craniotomy. With the help of 3DCEMRV, it has become possible to see the intracranial venous structures noninvasively. MR imaging technique with MIP method also presents more detailed information of brain surface structure by showing cortical veins $[3,4]$. The purpose of this study is to assess the usefulness of 3DCEMRV for the evaluation of intracranial venous system in preoperative surgical planning of brain tumors. In this study, we have compared the visibility of the intracranial venous system on 3DCEMRV with respect to those of 2DTOFMRV in surgical planning and compared it with intraoperative findings and also evaluated neurological outcomes postoperatively. In few cases post-operative MRV were done to look for any venous injury.

\section{MATERIAL AND METHODS}

\section{Patient population}

From May 2017 to Feb 2019, 48 patients were included which was admitted in department of neurosurgery Sawai Man Singh Medical College and Hospital, Jaipur. All patients underwent 3DCEMRV, as well as 2DTOFMRV in axial and sagittal planes.

\section{Method}

All the patients with midline supratentorial masses were selected on MRI brain images. After this cod liver oil capsules were placed on anterior and posterior ends of medial and lateral border of the tumour at scalp according to location of tumor on MRI images and thus, the tumour boundaries were marked with the help of permanent marker. Then MRV 2-DTOF image were taken in axial and sagittal view. After that, $0.4 \mathrm{ml} / \mathrm{kg}$ of gadolinium contrast agent was administered in cubital vein over 4 seconds and 3DCEMRV images were taken in axial and sagittal plane. All MR examinations were performed with 3-Tesla unit. All MR venographic source images were postprocessed with a maximum-intensity projection (MIP) algorithm to create projection venograms for both the 2DTOF MRV and the 3DCEMRV. All images were saved in DICOM software. The marked area concerned, superficial cortical veins such as frontopolar vein, anterior frontal vein, middle frontal vein, posterior frontal vein, precentral vein, central vein, post central vein, anterior parietal vein, posterior parietal vein and occipital vein and bridging veins joining the superior sagittal sinus were studied preoperatively. Sagittal sinus compression were also evaluated, which was defined as a narrowing and filling defect of the lumen. On the basis of these informations and surgeons preference the surgical corridor was decided. Intraoperative findings were compared with that of 3DCEMRV images and intraoperative photographs of cortical veins were taken. In few cases post operative MRV were done to look for any venous injury. All patients neurological status were assessed.

\section{Inclusion Criteria}

Conscious, co-operative and stable patients with supratentorial midline brain tumors.

\section{Exclusion Criteria}

Unconscious, uncooperative and unstable stable Allergic to gadolinium Ferromagnetic cardiac pacemakers, aneurismal clip and defibrillators. Claustrophobia

\section{Image analysis}

Degree of visualization and patency of the intracranial venous system, superficial as well as superior sagittal sinus on 3DCEMRV was compared with those of 2DTOF in capsule marked tumoral area. The image quality of 8 predefined venous structures was graded as follows: intense and continuous $=3$, faint and continuous $=2$, noncontinuous $=1$, and invisible $=0$. In post 
operative period, in few cases MRV were done to look for any venous injury.

\section{Ethical consideration}

The study protocol was approved by ethical Committee. All patient gave written informed consent to participate after having received full written information about the study objective and conducts. Investigations were done using aseptic precautions. They had right to withdraw from study. Protection was given from any kind of harm. Full confidentiality of data was maintained. No religious issues involved. All religious customs were respected. Study was conducted under supervision.

\section{Statistical analyses}

Statistical analyses were done using computer software (SPSS Trial version 23 and primer). The qualitative data were expressed in proportion and percentages and the quantitative data expressed as mean and standard deviations. The difference in proportion was analyzed by using chi square test. Significance level for tests were determined as 95\% $(P<0.05)$.

\section{RESULT}

In our study, a total of 48 patients were included, in which 25 were males and 23 were females. All patients were conscious, oriented and Glasgow coma scale was $15 / 15$ at the time of admission. Most of the cases were $16-60$ years (91.6\%) of age, followed by elderly (>60 years) (4.4\%) (Table no.1). Chi-square $=0.008$ with 2 degrees of freedom; $P=$ 0.996 NS. No significant difference was observed according to age groups and gender. No significant difference was observed in age among the male and females $(P=0.42 \mathrm{NS})$. Among 48 cases, 20 were parafalcine and 28 were parasagittal. Majority of the cases were located in frontal lobe. Most common clinical manifestation were found to be headache (85.4\%) followed by seizure (14.5\%) and limb weakness (12.5\%). We found 2 patients with diminution of vision and 2 cases of bladder disturbances (Table no.2). Most common histological diagnosis was found to be meningioma (60.4\%) followed by glioma(29.1\%) and epidermoid cyst (6.25\%) with 1 case of colloid cyst and 1 case of AVM (Table no.3). All lesions (100\%) were circumscribed precisely through small craniotomy.
Number of veins visualized in capsule marked area were as follows : Anterior frontal vein (12), Middle frontal vein (20), Posterior frontal vein (26), Central vein (11), Anterior parietal Vein (7), Posterior parietal vein (2), Occipital vein (1) and Superior Sagittal Sinus (48). The Mean grading score of imaging of individual superficial cortical veins were superior in 3DCEMRV as compared to 2DTOF (Table no. 4).

Poor depiction (Grade 2, 1, 0) of superficial cortical vein was observed in 26 cases $(54.16 \%)$ in 2DTOF $(\mathrm{N}=48)$ as compared to 3DCEMRV $(\mathrm{N}=48) 0$ $(0 \%)$. Whereas Clear depiction (Grade 3 ) of superficial cortical vein was observed in 48 cases $(100 \%)$ in 3DCEMRV $(\mathrm{N}=48)$ as compared to 2DTOF $(\mathrm{N}=48) 22$ case $(45.8 \%) \mathrm{P}<0.001 \mathrm{~S}$. (100\%) showed in 3DCEMRV. In addition to this, we also found extra other small cortical vein drain the superior sagittal group in $7(14.5 \%)$ cases in 3DCEMRV as compared to 2DTOF. Poor depiction (Grade 2, 1, 0) of superficial sagittal sinus was observed $15(31.2 \%)$ in 2DTOF $(\mathrm{N}=48)$ as compared to 3DCEMRV $(\mathrm{N}=48) 0(0 \%)$.whereas Clear depiction (Grade 3 ) of superior sagittal sinus was observed $48(100 \%)$ in 3DCEMRV $(\mathrm{N}=48)$ as compared to 2DTOF ( $\mathrm{N}=48) 33$ (68.6\%) P<0.001S (Table no.5). 14 case $(29.1 \%)$ showed sagittal sinus compression in both study groups. No new vein encountered during surgery. In post operative CT Head, we found 4 (8.3\%) cases of infarction, 1 (2.0\%) post operative site hematoma, and 3 (6.2\%) cases of pneumocephalus. No residual mass was present in any cases. In the present study 5 patients (10.4\%) developed neurological manifestations post operatively in the form of newly developed motor weakness, 4 patients (8.3\%) developed altered sensorium and 1 patient died in post operative period, no patient developed seizure. In 3 cases, post operative MRV were done and these were analysed with respective preoperative images and no venous injury were identified.

\begin{tabular}{|l|l|l|l|}
\hline $\begin{array}{l}\text { Age } \\
\text { group } \\
\text { (years) }\end{array}$ & Total no. of & Male & Female \\
\hline$\leq 18$ & $2(4.1 \%)$ & $1(2.0 \%)$ & $1(2.0 \%)$ \\
\hline $18-60$ & $44(91.6 \%)$ & $23(47.9 \%)$ & $21(43.7 \%)$ \\
\hline
\end{tabular}




\begin{tabular}{|l|l|l|l|}
\hline$\geq 60$ & $2(4.1 \%)$ & $1(2.0 \%)$ & $1(2.0 \%)$ \\
\hline total & $48(100 \%)$ & $25(52 \%)$ & $23(47.91 \%)$ \\
\hline Mean $\pm S$ & $42.08 \pm 12.1$ & $40.72 \pm 11.7$ & $43.57 \pm 12.1$ \\
D & 5 & 3 & 5 \\
\hline
\end{tabular}

\begin{tabular}{|c|c|c|c|}
\hline & $\begin{array}{l}\text { patients } \\
(\mathrm{N}=48)\end{array}$ & & \\
\hline $\begin{array}{l}\text { Anterior } \\
\text { frontal } \\
\text { vein }\end{array}$ & 12 & $2.29 / 3.0$ & 3DCEMRV \\
\hline $\begin{array}{l}\text { Middle } \\
\text { frontal } \\
\text { vein }\end{array}$ & 20 & $2.4 / 3.0$ & 3DCEMRV \\
\hline $\begin{array}{l}\text { Posterior } \\
\text { frontal ein }\end{array}$ & 26 & $2.3 / 3.0$ & 3DCEMRV \\
\hline $\begin{array}{l}\text { Central } \\
\text { vein }\end{array}$ & 11 & $2.36 / 3.0$ & 3DCEMRV \\
\hline $\begin{array}{l}\text { Anterior } \\
\text { parietal } \\
\text { vein }\end{array}$ & 7 & $2.51 / 3.0$ & 3DCEMRV \\
\hline $\begin{array}{l}\text { Posterior } \\
\text { parietal } \\
\text { Vein }\end{array}$ & 2 & $2.8 / 3.0$ & 3DCEMRV \\
\hline $\begin{array}{l}\text { Occipital } \\
\text { vein }\end{array}$ & 1 & $3.0 / 3.0$ & NONE \\
\hline $\begin{array}{l}\text { Superior } \\
\text { Sagittal } \\
\text { Sinus }\end{array}$ & 48 & $(2.6 / 3.0)$ & 3DCEMRV \\
\hline
\end{tabular}

Table 2. Clinical manifestations of patients.

\begin{tabular}{|l|l|}
\hline Histological diagnosis & No. of cases \\
\hline Meningioma & $29(60.4 \%)$ \\
\hline Glioma & $14(29.1 \%)$ \\
\hline Epidermoid cyst & $3(6.25 \%)$ \\
\hline Colloid cyst & $1(2.0 \%)$ \\
\hline AVM & $1(2.0 \%)$ \\
\hline Total & $48(100 \%)$ \\
\hline
\end{tabular}

Table 3. Distribution of patients based on histological diagnosis.

No. of cases

$41(85.4 \%)$

\section{Motor deficit}

$6(12.5 \%)$

\begin{tabular}{|l|l|}
\hline seizure & $7(14.5 \%)$ \\
\hline
\end{tabular}

Diminution of vision

$2(4.1 \%)$

$2(4.1 \%)$

Bladder disturbances

Superficial

\begin{tabular}{|l|l|l|l|}
\hline Superficial & Total & Mean & 2D TOF \\
veins & number & grading & /3DCEMRV \\
& veins & score & (SUPERIOR) \\
& visualisation & (2DTOF & \\
& in capsule & /3DCEMRV) & \\
& marked area & & \\
& in all & & \\
& & & \\
\hline
\end{tabular}

Table 4. Comparative study of image quality of individual superficial cortical veins in 2DTOF and 3DCEMRV according to mean grading score.

\begin{tabular}{|l|l|l|l|l|}
\hline Veins & Poor image & Clear & Poor image & Clear \\
& ( Grade & image & ( Grade & image \\
& $2,1,0)$ & (Grade 3) & $2,1,0)$ & (Grade 3) \\
& 2DTOF & 2D TOF & 3DCEMRV & \\
\hline
\end{tabular}




\begin{tabular}{|c|c|c|c|c|}
\hline & & & & $\begin{array}{l}\text { 3DCEMR } \\
\mathrm{v}\end{array}$ \\
\hline $\begin{array}{l}\text { Superfi } \\
\text { cial } \\
\text { cortical } \\
\text { veins }\end{array}$ & $\begin{array}{l}26 \\
(54.16 \%)\end{array}$ & $\begin{array}{l}22 \\
(45.8 \%)\end{array}$ & $0(0 \%)$ & $\begin{array}{l}48 \\
(100 \%)\end{array}$ \\
\hline $\begin{array}{l}\text { Superi } \\
\text { or } \\
\text { sagittal } \\
\text { sinus }\end{array}$ & $15(31.2 \%)$ & $\begin{array}{l}33 \\
(68.7 \%)\end{array}$ & $0(0.0 \%)$ & $\begin{array}{l}48(100 \\
\%)\end{array}$ \\
\hline $\begin{array}{l}\text { Other } \\
\text { small } \\
\text { cortical } \\
\text { vein } \\
\text { seen }\end{array}$ & NONE & NONE & $2(4.1 \%)$ & $\begin{array}{l}5(10.4 \% \\
)\end{array}$ \\
\hline $\begin{array}{l}\text { P Value } \\
\text { (2DTOF } \\
\text { /3DCE } \\
\text { MRV) }\end{array}$ & $<0.001 \mathrm{~S}$ & $<0.001 \mathrm{~S}$ & $<0.001 \mathrm{~s}$ & $<0.001 \mathrm{~S}$ \\
\hline
\end{tabular}

Table 5. Comparison of the image quality of superficial cortical veins and superior sagittal sinus in 2DTOF, 3DCEMRV.

\begin{tabular}{|l|l|}
\hline $\begin{array}{l}\text { Post operative clinical status } \\
\text { of patients }\end{array}$ & No. of patients \\
\hline Altered sensorium & $4(8.3 \%)$ \\
\hline $\begin{array}{l}\text { Newly developed motor } \\
\text { deficit }\end{array}$ & $5(10.4 \%)$ \\
\hline Seizure & $0(0 \%)$ \\
\hline Death & $1(2.0 \%)$ \\
\hline
\end{tabular}

Table 6. Post-operative neurological manifestations.

\begin{tabular}{|l|l|}
\hline Post-operative CT Head & No. of patient \\
\hline Venous infarction & $4(8.3 \%)$ \\
\hline $\begin{array}{l}\text { Post operative site } \\
\text { hematoma }\end{array}$ & $1(2.0 \%)$ \\
\hline Residual mass & $0(0.0)$ \\
\hline pneumocephalus & $3(6.2 \%)$ \\
\hline
\end{tabular}

Table 7. Post-operative CT head.

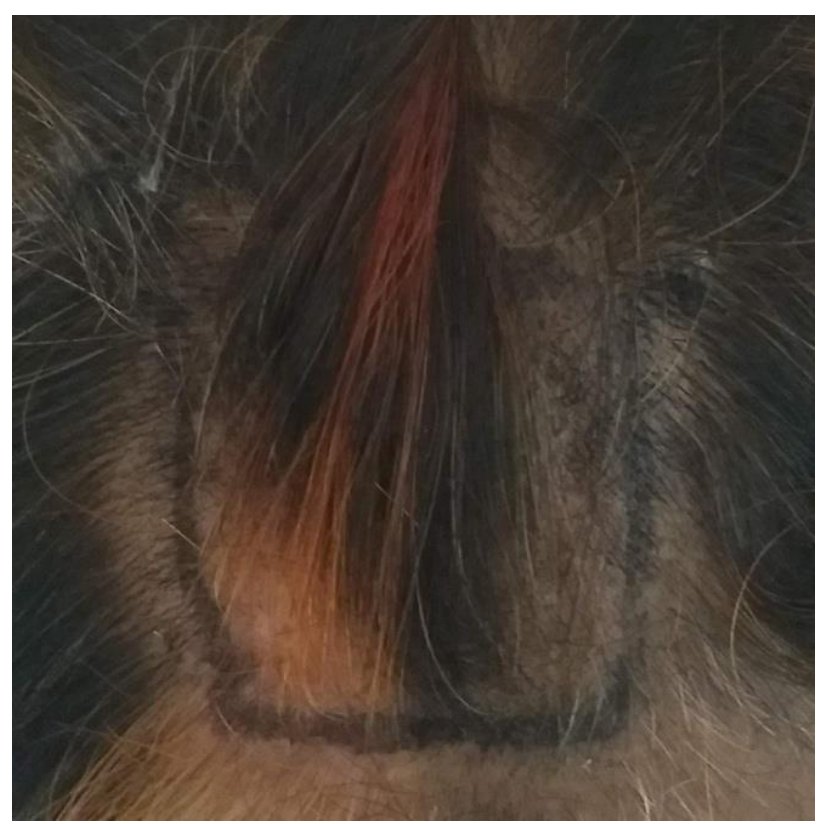

Figure 1. Image showing preoperative tumour marking with help of cod liver oil capsule.

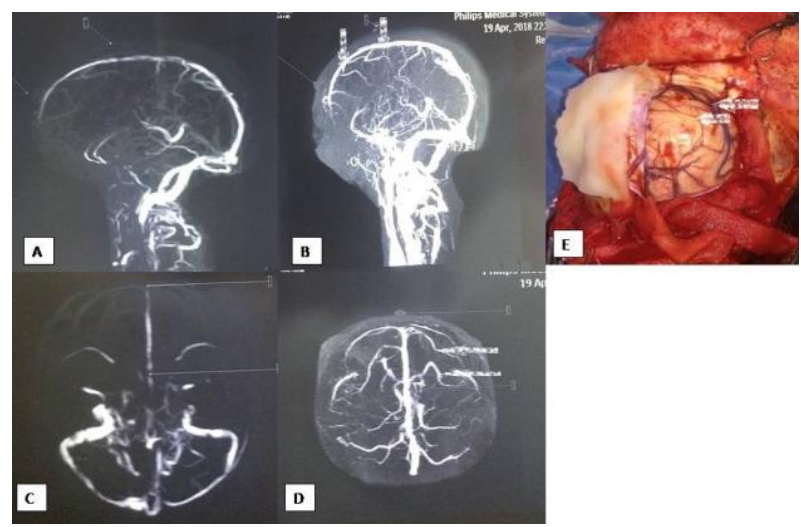

Figure 2. Comparison of 2D TOF and MR 3D CE MRV venography. Thick white arrow denotes superficial cortical veins (anterior and middle frontal vein) and thin arrow denote capsule in the anterior and posterior border of tumoral area. (A: Sagittal view; C: Axial view) 2D TOF MRV, (B: Sagittal view; D: Axial view) 3D CE MRV, showing clear visualization of anterior and middle frontal vein and entire superior sagittal sinus in 3DCEMRV. (E) Intraoperative photograph arrow showing 
superficial cortical vein (anterior and middle frontal vein) in defined marked area.

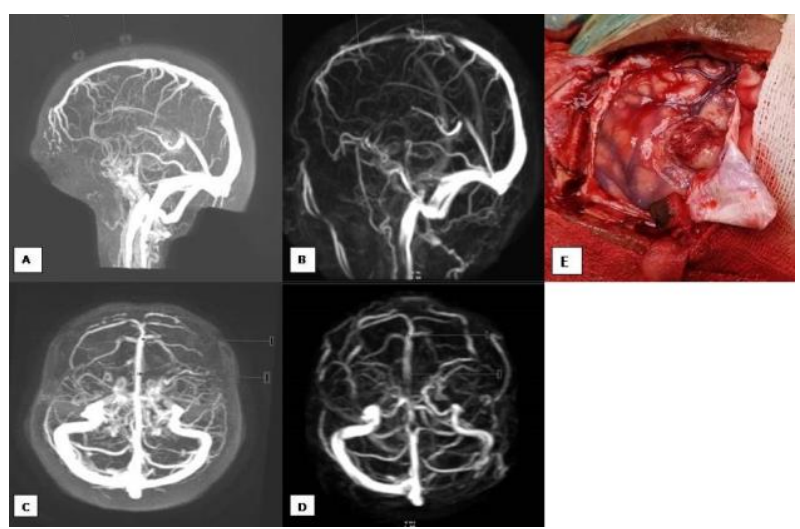

Figure 3. Comparison of preoperative and postoperative superficial cortical vein on MR venography. Thin arrow denote capsule in the anterior and posterior border of tumoral area. (A: sagittal view; C: Axial view) showing preoperative MRV and (B: sagittal view; D: Axial view) showing postoperative $M R V$, suggests that no superficial cortical venous injury in defined tumoral and peritumoral area. (E); Intraoperative photograph showing superficial cortical vein in defined marked area.

\section{Discussion}

Exact localization of superficial cortical venous system anatomy with respect to midline masses is very important in planning neurosurgical operations. On the basis of the cortical area that they drain, the superficial cortical veins are divided into four groups of bridging veins,:1. superior sagittal group, which drains into the SSS; 2 . sphenoidal group, which drains into the sphenoparietal and cavernous sinuses;3. tentorial group, which converges on the sinuses in the tentorium; and 4. falcine group, which empties into the inferior sagittal sinus or straight sinus[5]. Surgery for midline masses such as colloid cyst, DACA Aneurysm, Corpus callosal gliomas, parasagittal and parafalcine masses are synonymous with dissection of the veins surrounding the tumour, specifically the cortical parasagittal and bridging veins, superior sagittal sinus (SSS) and collateral venous channels [6]. These information on intracranial venous system anatomy can be obtained by TOF MRV and CE MRV which are noninvasive techniques. Generally, MRV is performed without using contrast agent through 2D TOF MR venographic techniques [7]. 2D TOF MRV has been widely accepted for the imaging of intracranial venous system despite the well known technique associated pitfalls. A major pitfall of TOF MRV is the artifactual intravascular signal loss that occurs at predictable points in the intracranial venous anatomy [8]. . Images of higher spatial resolution are obtained in 3DCE MRV with less scanning time than 2D TOF MRV[9]. Common flow related artifact seen on 2D TOF MRV can be avoided with the use of 3D CE MRV as it is flow insensitive [10]. False-negative results can also occur in 3D CE MRV in patients with enhancing intracranial lesions, such as neoplasms adjacent to dural sinus or veins. [11]. However, various literatures have reported that administration of contrast agent help to highlight these vessels especially small veins and also improve the vascular visualisation [12,13,14,15]. In our study $54.16 \%$ and $45.8 \%$ cases were having poor (grade $2,1,0$ ) and clear (grade 3 ) depiction of superficial cortical vein respectively on 2DTOF whereas all cases (100\%) showed clear (grade 3 ) depiction of studied vein in 3DCEMRV. Also, $68.7 \%$ and $100 \%$ cases showed clear depiction (grade 3 ) of superior sagittal sinus in 2DTOF and 3DCEMRV respectively. The mean grading score of imaging of individual superficial cortical veins were superior in 3DCEMRV as compared to 2DTOF. Thus the results of present study indicate better efficacy of 3DCEMRV over 2DTOFMRV. Study done by Leach et al;[16] also showed gadolinium-enhanced MRV to be superior than TOF MRV and also suggested the best evaluation using MRI. In the present study, the area over the tumor was marked by putting cod liver oil capsules, overlying veins were identified on 2DTOF MRV and 3DCEMRV image after that the surgical corridor was decided. Thus preoperative decision of surgical corridor allowed us to preserve the cortical veins maximally. In the study done by Burtscher et al. [17] have shown that 3-D image technique revealed additional information compared with conventional 2-D images and had an influence on neurosurgical planning and strategy, improving neurosurgical performance and patient outcome. In the present study also, additional other small cortical vein were found in 3DCEMRV in 7(14.5\%) cases as compared to 2DTOF. Information about tumour and overlying superficial cortical veins and sagittal sinus in the marked area are obviating the need for the surgeon to mentally reconstruct the surgical anatomy from 2$D$ image. Thus, orientation would be faster and more comprehensible $[18,19,20]$. With this information, the surgeon can plan the best approach for surgery. In the study by Khu et al; also concluded that 
knowing the exact location of cortical vein with respect to tumor helps in preserving them during surgery. In our study, 2DTOF and 3DCEMRV images were taken and found that 2DTOF images showed less depiction of superficial cortical veins in the marked area as compared to 3DCEMRV, thus suggesting 3DCEMRV as preferred modality for locating veins. Abnormal radiological findings of intracranial venous structures were confirmed with intraoperative findings. In the study done by R.Klingebiela et al.[22]; observed that Image quality was superior $(4.3 \pm 0.8 ; \mathrm{P}<0.001)$ for 3DCEMRV as compared with 2D TOF MRV (3.1 \pm 0.7$)$. In our study assessment of the evaluated sinus and veins was significantly improved by using 3DCEMRV $(P<0.05)$ as compared with 2D TOF MRV. Superior depiction of the cerebral venous anatomy on maximum intensity projection images from 3DCEMRV [22]. So 3DCEMRV is more informative than 2DTOF in delineation of superficial cortical and superior sagittal vein for surgical planning. and to avoid the venous injury while operating. All the patients were followed up and 5 (10.4\%) patients developed neurological manifestations post operatively in the form of newly developed motor weakness, 4 (8.3\%) patients developed altered sensorium and 1 patient died in post operative period. In post operative CT Head, we found $4(8.3 \%)$ cases of infarction , 1 (2.0\%) post op site hematoma, and $3(6.2 \%)$ cases of pneumocephalus. No residual mass was present in any cases. In 3 cases, post operative MRV were done and these were compared with respective preoperative images and no venous injury were identified. Evaluation of preoperative and postoperative MRV can be useful in assessment of venous injury. Our study had the following limitations: There was low statistical impact because of a small number of patients. Furthermore, cerebral venous thrombosis could not be detected in any of the participants; thus, the drawing of conclusions from these data about the performance of CE MRV and MPRAGE sequences in the detection of venous thrombosis remains difficult

\section{CONCLUSIONS}

This study showed that preoperative localization and evaluation of tumoral area and cortical veins with the help of cod liver oil in MRI and MRV brain was very helpful in planning the surgery, making craniotomy and to avoid injury of the veins. This technique is easy to perform and the capsule is easily constructed and inexpensive. 3DCEMRV was found to be better modality than 2DTOF for delineation of veins. Final neurosurgical outcomes were better.

\section{ABBREVIATIONS}

3dcemrv: 3-dimensional contrast enhanced magnetic resonance venography;

2dtof: 2-dimensional time of flight;

daca: distal anterior cerebral artery;

mrv: magnetic resonance venography;

ct: computed tomography;

sss: superior sagittal sinus;

mip: maximum-intensity projection;

sd: standard deviationism: arteriovenous malformation.

\section{REFERENCES}

1. Sekhar LN, Chanda A, Morita A (2002) The preservation and reconstruction of cerebral veins and sinuses. J Clin Neurosci 91(4):391-399. doi:10.1054/jocn.2001.1008

2. Andrews BT, Dujovny M, Mirchandani HG, Ausman JI (1989) Microsurgical anatomy of the venous drainage into the superior sagittal sinus. Neurosurgery 24:514520.

3. Katada K, Anno H, Takeshita G. MR images of brain surface anatomy scanning (SAS). Jpn J Magn Reson Med 1990;9:215- 25.

4. Katada K. MR imaging of brain surface structures: surface anatomy scanning (SAS). Neuroradiology 1990;32:43948.

5. Oka K, Rhoton AL, Barry M, Rodriguez R (1985) Microsurgical anatomy of the superficial veins of the cerebrum. Neurosurgery 17 (5):711-748. doi:10.1097/00006123-198511000-00003

6. Hancq S, Baleriaux D, Brotchi J (2003) Surgical treatment of parasagittal meningiomas. Semin Neurosurg 14:203210.doi:10.1055/s-2004-828923

7. Chakeres DW, Schmalbrock P, Brogan M, Yuan C, Cohen L. Normal venous anatomy of the brain: demonstration with gadopentetate dimeglumine in enhanced threedimensional MR angiography. AJR Am J Roentgenol 1991;156:161 - 72 .

8. Farb RI, Scott JN, Montanera WJ, Wright GA, Terbrugge KG. Intracranial venous system: Gadolinium-enhanced three-dimensional MR venography with auto-triggered elliptic centric-ordered sequenceinitial experience. Radiology 2002;226:203 - 9

9. Ayanzen RH, Bird CR, Keller PJ, McCully FJ, Theobald MR, Heiserman JE. Cerebral MR venography: normal anatomy and potential diagnostic pitfalls. AJNR Am J Neuroradiol 2000; 21: 74-78

10. Farb RI, Scott JN, Montanera WJ, Wright GA, Terbrugge KG. Intracranial venous system: Gadolinium-enhanced three-dimensional MR venography with auto-triggered 
elliptic centric-ordered sequenceinitial experience. Radiology 2002;226:203 - 9.

11. Lewin S, Masaryk TJ, Smith AS, Ruggrieri PM, Ross JS. Time-offlight intracranial MR venography: evaluation of the sequential oblique section technique. AJNR Am J Neuroradiol 1990;15:1657 - 64.

12. Chakeres DW, Schmalbrock P, Brogan M, Yuan C, Cohen L. Normal venous anatomy of the brain: demonstration with gadopentetate dimeglumine in enhanced threedimensional MR angiography. AJR Am J Roentgenol 1991;156:161 - 72.

13. Creasy JL, Price RR, Presbrey T, Goins D, Partain CL, Kessler RM. Gadolinium-enhanced MR angiography. Radiology 1990;175:280 - 3

14. Ikawa F, Sumida M, Uozumi T, Kiya K, Kurisu K, Arita K, Satoh $H$. Demonstration of venous systems with gadolinium-enhanced threedimensional phase-contrast MR venography. Neurosurg Rev 1995;18:101 - 7.

15. Stevenson J, Knopp EA, Litt AW. MP-RAGE subtraction venography. A new technique. J Magn Reson Image 1995;5:239 - 41.

16. Leach JL, Strub WM, Gaskill-Shipley MF. Cerebral venous thrombus signal intensity and susceptibility effects on gradient recalled-echo MR imaging. Am J Neuroradiol. 2007;28:940-5.

17. Burtscher J, Kremser C, Seiwald M, Obwegeser A, Wagner M, Aichner F et al (1998) Three-dimensional computer assisted magnetic resonance imaging for neurosurgical planning in parasagittal and parafalcine central region tumors. Comput Aided Surg 3(1):27-32

18. Oka K, Rhoton AL, Barry M, Rodriguez R (1985) Microsurgical anatomy of the superficial veins of the cerebrum. Neurosurgery 17 (5):711-748. doi:10.1097/00006123-198511000-00003

19. Rosahl SK, Gharabaghi A, Shahidi UH, Samii M (2006) Virtual reality augmentation in skull base surgery. Skull Base 16(2):59- 66. doi:10.1055/s-2006-931620

20. Chua GG, Serra L, Kockro RA, Hern N, Nowinski WL, Chan C (1998) Volume-based tumor neurosurgery planning in the Virtual Workbench. Virtual Reality Annual International Symposium, 1998. Proceedings IEEE: 167173

21. Kathleen Joy Khu \& Ivan Ng \& Wai Hoe Ng; The relationship between parasagittal and falcine meningiomas and the superficial cortical veins: a virtual reality study; Acta Neurochir (2009) 151:1459-1464 DOI 10.1007/s00701-009-0379.

22. R. Klingebiela, H.C. Bauknechta, G. Bohnera, R. Kirschb , J. Bergera and F. Masuhrc; Comparative evaluation of 2D time-of-flight and 3D elliptic centric contrastenhanced MR venography in patients with presumptive cerebral venous and sinus thrombosis, 2007 EFNS European Journal of Neurology 14, 139-143. 